Bangladesh Journal of Neuroscience 2019; Vol. 35 (1): 22-26

\title{
Socio Demographic and Headache Characteristics of Migraine Patients in a Tertiary Care Hospital in Bangladesh
}

\author{
BHATTACHARJEE M ${ }^{1}$, KARIM MR², HOSSAIN A ${ }^{3}$, MONDOL G ${ }^{4}$, BISWAS R ${ }^{5}$
}

\begin{abstract}
:
Migraine is a common type of headache. After tension type headache, it is the second common cause of primary headache disorder with a female preponderance. This cross sectional study was done toassess the sociodemographic characteristics of migraine patients in Bangladeshi population and to see the characteristics of headache and associated comorbidities of migraine patients. The study was conducted in a tertiary care hospital (Mymensingh medical college) of Bangladesh. The study subjects consisted

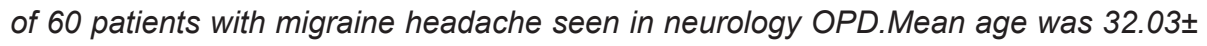
11.74 yrs. Male female ratio was 1: 2.7. Most of them are housewives (61.6\%). $22 \%$ had family history of headache. Most of the patients had severe (53.4\%) and frequent (e"3 per month) headache attacks. Aura was present in 25\% patients. Depressive illness was the associated comorbid condition which was found in $15 \%$ patients.
\end{abstract}

Key words: Migraine, Socio demography, Comorbidity

\section{Introduction:}

Migraine is a common type of headache. After tension type headache, it is the second common cause of primary headache disorder with a female preponderance. Migraine constitutes $16 \%$ of primary headache and it affects $10-20 \%$ of general population ${ }^{1}$. Lifetime prevalence ranging between 14 and $16 \%^{2}$. It is ranked as third highest cause of disability worldwide in both males and females under the age of 50 years $^{3}$. It is a unilateral, recurrent, episodic headache associated with nausea and or vomiting and sensitivity to light, sound or movement. Studies have revealed that $4-6 \%$ of men, $13-18 \%$ of women are afflicted with migraine worldwide over a 1 -year period ${ }^{4}$. It usually begins in adolescence but may occur in childhood. More than $80 \%$ of cases it begins before the age of 30 , and in $50 \%$ of cases before 20 years of age $^{5}$.World Health Organization declared migraine as the most disabling medical conditions experienced worldwide ${ }^{6}$. The indirect costs of migraine related to decreased productivity and lost days of work have been calculated to be $\$ 13$ billion per year ${ }^{7}$. The pathophysiology of migraine is still unclear. There are few hypothesises.Clinical and experimental evidence supports the concept of abnormal intracranial and extra cranial vascular reactivity in migraine and other vascular headaches.In 2018 the Third Headache Classification Committee of International Headache Society (IHS) published a detailed classification of Headache Disorders, the 3rd edition $^{8}$. In that edition Migraine headache is classified in six subtypes. There is evidence that the patients with migraine are often comorbid with other diseases, such as stroke, hypertension, diabetes, Bronchial Asthma, obesity and depression 9,10 . We believe that a nationwide

1. Dr. Manabendra Bhattacharjee, Associate Professor, Dept. of Neurology, Mymensingh Medical College, Mymensingh, Bangladesh

2. Dr. MD. Rezaul Karim, Registrar, Dept. of Neurology, Mymensingh Medical College hospital, Mymensingh, Bangladesh.

3. Dr. Akmal Hossain, Resident, Neurology (Phase B), Mymensingh Medical College, Mymensingh, Bangladesh

4. Dr. Gurudas Mondol, Associate Professor, Dept. of Neurology, National Institute of Neurosciences and Hospital, Dhaka, Bangladesh.

5. Dr. Rajib Biswas, Junior consultant (C.C) Medicine, Saturia UHC, Manikganj, Bangladesh 
epidemiological study of migraine in the general population is needed. And as a primary work, a hospital based study to asses the section of population with migraine headache and its characters would be helpful. Therefore, the aim of this study was to assess the sociodemographic characteristics of migraine patients in Bangladeshi population and to see the characteristics of headache and associated co morbidities of migraine patients.

Methods:

This cross-sectional study was carried out in the outpatient department of Neurology, Mymensingh Medical College Hospital, Bangladesh from January 2018 to Dec 2018. The patients were selected on the basis of International headache society (IHS) migraine headache criteria ${ }^{8}$.Total sixty patients with the typical history of migraine, age above 12 years were included in this study. Headache due to other than migraine and those were refused to include in this study were excluded.The clinical features, investigation findings and relevant data were collected in a preformed data sheet from each patient. Severity of headache was assessed by visual analogue scale. Co morbid conditions were assessed by relevant history and investigations. Depression was diagnosed on the basis of DSM-IV criteria. Informed written consent was taken from each participant. The study was approved by the Institutional review board (IRB) of Mymensingh Medical College. Analysis of data was done by SPSS version 23.

\section{Results:}

This cross-sectional study was done on 60 patients attending in outpatient department of Neurology, Mymensingh Medical College Hospital with migraine fulfilling the criteria of international headache society. Sociodemographic variables and characteristics of headache were assessed. Other co-morbidities were also documented.
Table-I

Characteristics of migraine patients $(n=60)$.

\begin{tabular}{lcc}
\hline Age(Years) & $\begin{array}{c}\text { Frequency } \\
(\mathrm{N}=60)\end{array}$ & Percentage \\
\hline$<20$ & 07 & 11.7 \\
$20-30$ & 27 & 45 \\
$31-40$ & 10 & 16.7 \\
$41-50$ & 11 & 18.3 \\
$>50$ & 05 & 8.3 \\
Mean \pm SD & $32.03 \pm 11.74$ & $32.03 \pm 11.74$ \\
Sex & & \\
Male & 16 & 26.7 \\
Female & 44 & 73.3 \\
Occupation & & \\
Housewife & 37 & 61.6 \\
Student & 10 & 16.7 \\
Business & 05 & 08.3 \\
Service & 04 & 6.7 \\
Others & 04 & 6.7 \\
Socioeconomic status & & 56.7 \\
Lower class & 30 & 50 \\
Middle class & 29 & 4.7 \\
Upper class & 01 & \\
Family history of headache & & \\
Present & 22 & \\
Absent & 38.3 \\
\hline
\end{tabular}

Table-1 demonstrates the socio demographic variables. The mean age of migraine patients was $32.03 \pm 11.74$ years. Highest no. of patients was in age group 20 to 30 years. Regarding gender distribution, $26.7 \%$ patients were male and $73.3 \%$ were female. Male to female ratio was 1: 2.75 . Maximum (61.6\%) patients were housewife. 50\% belongs from lower class and $48.3 \%$ were from middle class. Family history of headache was found in $36.7 \%$ patients. 
Table-II

Characteristics of headache of migraineurs $(n=60)$

\begin{tabular}{lcc}
\hline Characters & $\begin{array}{c}\text { Frequency } \\
(\mathrm{N}=60)\end{array}$ & Percentage \\
\hline $\begin{array}{l}\text { Severity of headache } \\
\quad \text { Mild }\end{array}$ & 04 & 6.6 \\
$\quad$ Moderate & 24 & 40 \\
$\quad$ Severe & 32 & 53.4 \\
$\begin{array}{l}\text { Frequency of headache } \\
\quad<3 \text { per month }\end{array}$ & 18 & 30 \\
$\quad \begin{array}{l}\text { 23 per month } \\
\text { Location of headache }\end{array}$ & 42 & 70 \\
$\quad$ Unilateral & 50 & 83.3 \\
$\quad$ Bilateral & 10 & 16.7 \\
$\begin{array}{l}\text { Type of migraine } \\
\quad \text { With aura }\end{array}$ & 15 & \\
$\quad$ Without aura & 45 & 75 \\
\hline
\end{tabular}

Table II demonstrates the headache characteristics. Quality of headache was moderate (40\%) to severe (53.4\%). Most of the patients $(70 \%)$ had headache frequency e"3 per month. Unilateral headache in $83.3 \%$ patients and migraine with aura was present in $25 \%$ patients whereas most of the patients $(75 \%)$ had migraine without aura.

Table-III

Distribution of migraine patients with various comorbid conditions $(n=60)$.

\begin{tabular}{llcc}
\hline & & $\begin{array}{c}\text { Frequency } \\
(\mathrm{n}=60)\end{array}$ & Percentage \\
\hline Hypertension & Present & 04 & 6.6 \\
IHD & Absent & 56 & 93.4 \\
& Present & 03 & 5 \\
Stroke & Absent & 57 & 95 \\
& Present & 02 & 3.3 \\
Epilepsy & Absent & 58 & 96.7 \\
& Present & 01 & 1.7 \\
Depression & Absent & 59 & 98.3 \\
& Present & 15 & 25 \\
& Absent & 45 & 75 \\
\hline
\end{tabular}

Table III shows the associated comorbidities with migraine headache, Very few cases had Hypertension, Ischemic heart disease, Stroke and Epilepsy. But 25\% patients had associated depression.

\section{Discussion:}

This Cross-sectionalstudy was carried out in outpatient department of Mymensingh medical college hospital, Mymensingh. Total 60 patients of migraine were studied according to selection criteria. Sociodemographic and headache characteristics were studied. Associated comorbid conditions were also assessed.

In the study $45 \%$ of the migraine patients were in the age group 20-30 years. Majority of the patients $(61.7 \%)$ were in $20-40$ years age group. Mean age of migraine patients was $32.03 \pm .74$ years. $26.7 \%$ were male and $73.3 \%$ were female. The male and female ratio were $1: 2.7$. Similar findings were observed in a study ${ }^{11}$ in Bangladesh in 2017 where the mean age was $33.8 \pm 8.8$ years. They found $76 \%$ patients were between 21-40 years. Male: female ratio was $1: 2.6$. Another study ${ }^{12}$ found nearly $79.6 \%$ patients were from 15-35 years and male: female ratio was $1: 1.7$.

In this study, house wives and students occupied the largest number of study subjects, $61.6 \%$ and $16.7 \%$ respectably. Hasanet al ${ }^{12}$ found housewife $43.7 \%$ and student $28.1 \%$. Boru et al. ${ }^{13}$ and Hossain et $\mathrm{al}^{11}$ also observed most of the migraine patients were house wives. Regarding socioeconomic status among migraine patient, $50 \%$ were of low income group and $48.3 \%$ were of middle class group. Only one patient from higher socioeconomic class may be due to lack of their presence in outpatient department. Stewart $(2013)^{14}$ mentioned migraine is more prevalent in low socioeconomic condition. A population based study ${ }^{15}$ was also found Migraine is more prevalent in low socioeconomic conditions. In our study we found more or less similar patients in these two groups, may be due to small sample size and hospital based study.

Family history of headache was present in $36.7 \%$ patients. Mixed findings were observed in different studies. Boru et al. ${ }^{13}$ reported positive family history in $33.1 \%$ cases of migraine which is similar of this study whereas Boes et al. ${ }^{16}$ found it in $90 \%$ of cases.

Regarding headache characteristics we found $53.4 \%$ patients had severe headache and $40 \%$ had 
moderate headache. Most of the patients (70\%) had headache frequency 3 or more per months and headache starts unilaterally $(83.3 \%)$. Hossain ${ }^{11}$ found $56.7 \%$ with severe headache. Gulet al ${ }^{17}$ found average 4.08 attacks per month. In this study, migraine with aura was $25 \%$ and migraine without aura was $75 \%$ and ratio was $1: 3$. In previous cross sectional population study ${ }^{18}$ the ratio was 1:5.

Migraine with associated comorbid conditions, we found very few percentage of patients with Hypertension, Ischemic heart disease, Stroke and Epilepsy. But over 15\% patients had associated depression. In Buse et al study ${ }^{19}$, they found people with migraine were significantly $(P<0.001)$ more likely to report insomnia (OR $3.79[3.6,4.0]$ ), depression (OR 3.18 [3.0, 3.3]), anxiety (OR 3.18 [3.0 3.3], angina or IHD (OR $2.64[2.4,3.0]$ ). Hossain ${ }^{11}$ found $18.2 \%$ patients had Major depressive disorder and $24.2 \%$ had generalised anxiety disorders.

\section{Limitation:}

It was a hospital based study with small sample size, so complete epidemiological statistics might not been achieved what would have been assessed in a large community study.

\section{Conclusion:}

In conclusion, from this study we found migraine is more common in 20-40 years age group and females are more sufferer than males and most of them are housewives. $22 \%$ had family history of headache. Most of the patients had severe and frequent headache. Aura was present in $25 \%$ patients. Depressive illness was the associated comorbid condition which was found in $15 \%$ patients. Further large community study should be carried out for better understanding of demographic and clinical characteristics of this prevalent disorder.

\section{References:}

1. Goadsby, PJ, Lipton, R \& Ferrari, MD, 'Migraine - Current understanding and treatment', N Engl J Med, 2002;3(46): 257-70

2. LjStovner, Hagen K, Jensen R. The global burden of headache: a documentation of headache prevalence and disability worldwide.Cephalalgia2007;27:193-210

3. Timothy J. Steiner, Lars J. Stovner, Theo Vos. GBD 2015: Migraine is the third cause of disability in under 50s: J Headache Pain. 2016; 17(1): 104.

4. Goadsby, P.J. and Raskin, N.H, Migraine and other primaryHeadache disorders, In: Stephen L. and Andrew S. (eds, Harrison's Neurology in Clinical Medicine, $4^{\text {th }}$ ed, McGraw Hill Education, 2017; 376-391.

5. Goadsby, P.J. andRaskin, N.H., Headache, In: Hauser SL, Josephson SA. (eds), Harrison's Neurology in clinical Medicine, $3^{\text {rd }}$ edition, McGraw-Hill, USA, 2013; 53.

6. Garza, I., Jerry, W., Swanson, William, P., Cheshire, J., Boes, C.J., et al., Headache and other craniofacial pain. In: Robert B., Gerald M., Joseph J., John C.(eds), Bradley's Neurology in Clinical Practice, $6^{\text {th }}$ ed, Elsevier Saunders, Philadelphia, 2012;1:1703-1744.

7. Lipton, R.B., Stewart, W.F., Diamond, S., Diamond, M.L., Reed, M., ,Prevalence and burden of migraine in the USA: Data from the American migraine Study-II. Headache, 2001;41:646.

8. Olesen, J. and Steiner, T.J., 2018, The international classification of headache disorders, $3^{\text {rd }}$ edition (ICHD-3). Cephalagia, 2018; 38(1) :1-211.

9. Scher Al, Bigal ME, Lipton RB) Comorbidity of migraine. CurrOpinNeurol.2005;18:305310

10. Tietjen GE, Herial NA, Hardgrove J, Utley C, White L Migraine co-morbidity constellations. Headache 2007;47:857-865

11. Hossain MA, Hakim M , Hasan M , Rahman MA ,Rashid M , Sagir G , Hussain ME. 2017, Journal of National Institute of Neurosciences Bangladesh, January 2017;:3(1):48-51.

12. Hasan MK, Khan I, Salam T,Sharmin M.The Sociodemographic Characteristics of Migraine Patients in Bangladesh .Int J Med Res Prof.2019 Nov; 5(6); 59-62. 
13. Boru, U.T., Kocer, A., Luleci, A., Sur, H., Tutkan, H. and Atli, H., Prevalence and characteristics of migraine in womanof reproductive age in Istambul, Turkey; A population based survey.Tohoku J. Exp. Med., 2005, 206 (1), 51-59.

14. Stewart, W.F., Lipton, R.B. and Roy, J., 2013. Migraine Prevalence, socioeconomic status and social causation. Neurology 2013 Sep 10;81(11):948-55.

15. Fernández-de-las-Peñas, C., HernándezBarrera, V., Carrasco-Garrido, P. et al. Population-based study of migraine in Spanish adults: relation to socio-demographic factors, lifestyle and co-morbidity with other conditions. J Headache Pain 2010;11: 97-104

16. Boes, C.J., Capobianco, D.J., Cutrer, F.M., Dodick, D.W., Garza, I., Swanson et al., 2008, Headache and other craniofacial pain. In: Robert B, Daroff, Gerald M, Fonichol,
Jankovic J, Mazziotta J, $5^{\text {th }}$ edn. Breadly's Neurology in clinical practice, Philadelphia, Butterworth-Heinemann Elsevier, 2:2011-62.

17. Gül FC,Hikmet $s$, Tülin $A$, Yunus $h$. Comparison of patients with migraine and tension-type headache in terms of somatosensory amplification and health anxiety. Arq. Neuro-Psiquiatr. [Internet]. 2019 Nov [cited 2020 Sep 11] ; 77(11): 768-774

18. Ropper, A.H. and Brown, R.H. 2005, Headache and other craniofacial pains, In: Adams and Victor's Principles of Neurology, $8^{\text {th }}$ ed., New York, McGraw-Hill Book Inc: 144-67.

19. Buse D C, Reed M L, Fanning K L, Bostic R, Dodick DW, Schwedt T J, et al.Comorbid and co-occurring conditions in migraine and associated risk of increasing headache pain intensity and headache frequency: results of the migraine in America symptoms and treatment (MAST) study. The Journal of Headache and Pain 2020; 21(23): 1-16. 